This item was submitted to Loughborough's Research Repository by the author.

Items in Figshare are protected by copyright, with all rights reserved, unless otherwise indicated.

\title{
Acoustic quasi-steady response of thin walled perforated liners with bias and grazing flows
}

\section{PLEASE CITE THE PUBLISHED VERSION}

https://doi.org/10.1016/j.jsv.2017.10.002

\section{PUBLISHER}

(c) Elsevier

\section{VERSION}

AM (Accepted Manuscript)

\section{PUBLISHER STATEMENT}

This work is made available according to the conditions of the Creative Commons Attribution-NonCommercialNoDerivatives 4.0 International (CC BY-NC-ND 4.0) licence. Full details of this licence are available at: https://creativecommons.org/licenses/by-nc-nd/4.0/

\section{LICENCE}

CC BY-NC-ND 4.0

\section{REPOSITORY RECORD}

Regunath, Gavita S., Jochen Rupp, and Jon Carrotte. 2017. "Acoustic Quasi-steady Response of Thin Walled Perforated Liners with Bias and Grazing Flows”. Loughborough University. https://hdl.handle.net/2134/26914. 


\title{
Acoustic Quasi-Steady Response of Thin Walled Perforated Liners with Bias and Grazing Flows
}

\author{
G. Regunath ${ }^{\mathrm{a}}$, J. Rupp ${ }^{\mathrm{a}}$, J. Carrotte ${ }^{\mathrm{a}}$
}

UTC, Department AACME, Loughborough University, Ashby Road, Loughborough, UK LE11 3TU

\begin{abstract}
This paper considers the acoustic performance of a passive damper in which acoustic energy is absorbed by orifices located within a thin plate (i.e. a perforated liner). The perforated liner, which incorporates orifices of length to diameter ratios of $\sim 0.2$, is supplied with flow from a passage. This enables the liner to be subject to a flow that grazes the upstream side of each liner orifice. Flow can also pass through each orifice to create a bias flow. Hence the liner can be subjected to a range of grazing and bias flow combinations. Two types of liners were investigated which incorporated either simple plain or 'skewed' orifices. For the mean flow field, data is presented which shows that the mean discharge coefficient of each liner is determined by the grazing to bias flow velocity ratio. In addition, measurements of the unsteady flow field through each liner were also undertaken and mainly presented in terms of the measured admittance. For a given liner geometry, the admittance values were found to be comparable for a given Strouhal number (with the exception of the lowest bias to grazing flow velocity ratio tested) which has also been noted by other authors. The paper shows that this is consistent with the unsteady orifice flow being associated with variations in both the velocity and the area of the vena contracta downstream of each orifice. These same basic characteristics were observed for both of the liner geometries tested. This provides a relatively simple means of predicting the acoustic liner characteristics over the specified operating range.
\end{abstract}

\section{Keywords}

Acoustic absorption; Orifice impedance; Bias flow; Grazing flow; Perforated liners 


\section{Nomenclature}

\begin{tabular}{|c|c|}
\hline$A_{d u c t}$ & Area of bias passage \\
\hline$A_{h}$ & Area of orifice \\
\hline$A_{\text {liner }}$ & Area of liner \\
\hline$A_{v c}$ & Area of vena contracta \\
\hline$c$ & Speed of sound \\
\hline$C_{d(p)}$ & Discharge coefficient for the plenum fed liner \\
\hline$C_{d}$ & Discharge coefficient \\
\hline D & Orifice diameter \\
\hline$H_{n}$ & Helmholtz number \\
\hline$k$ & Wave number \\
\hline$K_{R}$ & Orifice Rayleigh conductivity \\
\hline L & Orifice length \\
\hline$m_{\text {meas }}$ & Measured mass flow \\
\hline$p$ & Static pressure \\
\hline$p^{\prime}$ & Fluctuating pressure \\
\hline$\hat{p}_{i}$ & Incident acoustic wave \\
\hline$\hat{p}_{r}$ & Reflected acoustic wave \\
\hline$P$ & Total pressure \\
\hline$\hat{Q}$ & Orifice volume flux \\
\hline$Q^{\prime}$ & Unsteady volume flow \\
\hline $\mathrm{R}$ & Radius \\
\hline$R$ & Resistance \\
\hline St & Strouhal number \\
\hline$u^{\prime}$ & Fluctuating velocity \\
\hline$U$ & Mean velocity \\
\hline$U_{b}$ & Bias flow velocity \\
\hline$U_{g}$ & Grazing flow velocity \\
\hline$U_{j}$ & Jet flow velocity \\
\hline
\end{tabular}




$\begin{array}{ll}X & \text { Reactance } \\ Z & \text { Impedance } \\ \delta & \text { Admittance } \\ \delta_{q s} & \text { Quasi-steady conductivity } \\ \Delta \hat{p} & \text { Unsteady pressure drop } \\ \Gamma & \text { Inertia } \\ \rho & \text { Density } \\ \omega & \text { Angular frequency }\end{array}$

\subsection{Introduction}

Acoustic dampers are used for the suppression of noise in a wide range of applications that include, for example, automotive exhaust mufflers and liners for aircraft engines. In the presence of reacting flows, dampers may also be used to suppress instabilities that can potentially arise due to unsteady heat release. Typically a passive damper consists of a multitude of orifices located within a thin plate (i.e. a perforated liner) with open area ratios that can vary significantly (e.g. up to 20\%). To improve acoustic performance and/or ensure liner integrity (e.g. in hostile environments where hot gases dictate the need for liner cooling) flow may also be passed through the orifices to create a so called bias flow. In many practical engineering applications this bias flow is supplied from a passage, parallel to the liner, and a grazing flow is therefore created from which fluid can be drawn to pass through each orifice. Alternatively a grazing flow may also be present on the downstream side of the liner (i.e. into which the bias flow is passing). This paper considers the acoustic performance of a passive damper in which acoustic energy is absorbed by orifices located within a thin plate (i.e. a perforated liner). The liner is supplied with air from a passage and can therefore be subject to a range of both grazing and bias flows.

Numerous investigations have considered the absorption mechanisms associated with an orifice in which bias flow is supplied from an upstream plenum (i.e. no grazing flow). Examples include Bellucci, Flohr, \& Paschereit [1], Dowling \& Hughes [2], Forster \& Michel [3], Howe [4], Luong, Howe, \& McGowan [5]and Rupp [6]. A review of some of this work is also provided by Lawn [7]. In such studies the bias flow is usually modulated by a locally uniform time harmonic pressure differential $\Delta \hat{p}=\hat{p}(u s)-\hat{p}(d s)$ that results in an unsteady orifice volume flux $(\hat{Q})$. The acoustic properties of the orifice with bias flow can be described in a number of ways. For example, the Rayleigh conductivity of the orifice $\left(K_{R}\right)$ (as defined by Rayleigh [8]) relates the unsteady volume flow through the orifice to the unsteady pressure drop and is defined such that: 


$$
\frac{K_{R}}{2 R}=-\frac{i \omega \rho \hat{Q}}{\Delta \hat{p}}
$$

The Rayleigh conductivity for an orifice is unknown, but an analytical model was developed by Howe [4] for a circular orifice with a high Reynolds number bias flow that is being subjected to an unsteady pressure drop. The orifice was assumed to be infinitesimally thin, the bias flow large relative to the unsteady velocity amplitude, and the bias (or 'jet' flow) irrotational (but with vorticity being shed in a cylindrical shear layer from the edge of the aperture). The Rayleigh conductivity can be expressed such that:

$$
\frac{K_{R}}{2 R}=(\Gamma-i \delta)
$$

Expressions for the acoustic inertia $(\Gamma)$ and admittance $(\delta)$ were derived by Howe [4] which are functions of Strouhal number, with the amount of acoustic energy absorbed being proportional to the admittance. The derived expressions assume the acoustic absorption of an orifice is linear, which requires the unsteady velocity amplitude within the aperture to be significantly greater than the mean velocity through the orifice (i.e. $p^{\prime} \sim u^{\prime}$ for $u^{\prime} \ll \bar{U}$ where $p^{\prime}, u^{\prime}$ are time independent values). In this case the acoustic admittance and inertia of the orifice flow is independent of the incident excitation pressure amplitude, and the acoustic energy loss increases in proportion to the incident acoustic energy. This was further extended by Luong, Howe, \& McGowan [5] for conditions where the unsteady velocity amplitude approaches that of the mean bias flow velocity.

An alternative way of describing the acoustic behaviour of an orifice is in terms of impedance which has both resistive $(R)$ and reactive $(X)$ components. These can be related to the inertia and admittance such that:

$$
\frac{\Delta \hat{p}}{\hat{u}}=\mathrm{R}+i X=\frac{\pi \omega \rho \mathrm{R}}{2}\left(\frac{\delta}{\delta^{2}+\Gamma^{2}}-i \frac{\Gamma}{\delta^{2}+\Gamma^{2}}\right)
$$

Many experimental investigations into perforated liners have been undertaken in which a large number of orifices are incorporated and, through which, a bias flow passes. It is typically assumed that the distance between each orifice within the liner is large (relative to the orifice diameter) so that each orifice acts in isolation. This enables models, such as that outlined by Howe [4], to be applied and developed further. For example, Hughes \& Dowling [9] demonstrated how the acoustic absorption associated with a bias flow can be enhanced if a resonant cavity is formed by the orifice (or liner) being backed by a rigid wall. An analytical model was developed based on the theory of Howe [4] which provided good agreement with the acoustic measurements. A similar investigation was also undertaken by Dowling \& Hughes [2] but incorporated an array of slits, whilst Jing \& Sun 
[10] investigated similar arrangements and extended the theory of Howe [4] by adding an acoustic length correction to account for the finite thickness of the liner. Comparison with the measurements generally showed good agreement. Moreover Jing \& Sun [11] developed a numerical model of the shear layer downstream of the orifice by including more realistic orifice bias flow profiles, as measured by Rouse \& Abul-Fetouh [12] obtained from the steady state flows. It was intended to model the orifice length effects more realistically for orifice length to diameter ratios ranging from 0.4 to 0.6 . This model showed significant differences to the modified theory developed by Howe [4] and that outlined by Jing \& Sun [10]. Eldredge \& Dowling [13] applied this model to acoustic absorption measurements with a grazing flow across the perforated liner which was backed by a volume that was not in acoustic resonance. The developed model showed good agreement for the geometries considered. Note that in this case the absorption model took no account of grazing flow effects. Forster \& Michel [3] investigated the absorption of perforated plates (with open area ratios of between $4 \%$ and $20 \%$ ) and reported that the liner absorption could be increased within a Mach number range associated with the flow through the liner. Heuwinkel, Enghardt, \& Rohle [14] investigated experimentally various perforated liners of different porosity and subject to various bias and mean grazing flows. Observations of the data showed how the absorption was dependent on various factors. Furthermore, Lahiri, Enghardt, Bake, Sadig, \& Gerendas [15] developed an experimental database of the acoustic bulk properties relating to perforated liners and included variations in bias flow, liner porosity, liner thickness, grazing flow and orifice shape. In general, for many configurations reasonable agreement was obtained with the absorption model based on the conductivity model developed by Howe [4]. A summary of these investigations is given by Rupp [6].

More recent studies have utilised numerical (CFD based) methods to predict acoustic absorption. For example Mendez \& Eldredge [16] used Large Eddy Simulation (LES) to calculate the Rayleigh conductivity. The analytical model proposed by Howe [4] and the LES calculation compare reasonably well for the low frequency range. However, it was suggested that the analytical model needs to be modified for more sophisticated geometries and also needs to include the effect of liner thickness. These features can induce shear layers inside the aperture which gives rise to more complicated interactions between the acoustic energy and unsteady velocity fields. More recently Mendez \& Eldredge [16] compared the results from an LES study with various analytical absorption models. The LES based data was in good agreement with the more detailed model presented by Jing \& Sun [11] which used jet profiles. Hence, the profile of the jet is important to accurately predict the acoustic absorption of an orifice plate. In a similar way Andreini, Bianchini, Facchini, Simonetti, \& Peschiulli [17] used LES to investigate the flow fields of perforated liners and compared with the models developed by Howe [4] and Jing \& Sun [11] in addition to the results of Bellucci, Flohr, \& Paschereit [1]. The models did, in general, agree with the investigated orifice experiments but also showed differences with respect to the analytical models. It is also worth noting that the application of CFD to acoustic absorption processes is still challenging since it involves relatively large grid sizes and small time steps. The choice of suitable turbulence models (URANS) or sub-grid scale models 
(LES) also has an effect on the accuracy of the unsteady flow field prediction. Hence, at the current time it is argued there continues to be a need for accurate but relatively simple analytical or empirical models that enable the rapid optimisation of perforated liners during the initial design stages.

The aforementioned investigations indicate that the orifice unsteady flow (and the associated velocity profiles of the flow passing through each orifice) affects the acoustic absorption characteristics of a perforated liner. Furthermore, these velocity profiles will inevitably be influenced by the presence of a grazing flow. Whilst in some cases the effects may be relatively small, at other operating conditions significant differences arise between the measured absorption characteristics and that predicted by various analytical models. In many investigations the effects of bias or grazing flow are considered in isolation however, as described by Tonan, Moers, \& Hirschberg [18], a limited number of studies have considered various combinations of grazing and bias flows. From these studies it is clear the acoustic properties are dependent on the interaction of the two mean flow contributions (rather than a simple summation of grazing and bias flow effects). Rogers \& Hersh [19] initially considered a grazing and bias flow combination, but this study was limited to the steady state resistance of square-edged orifices. A discharge coefficient was defined that related the ratio of the actual to ideal (1D) flow rate through the orifice. Also presented were the different operating regimes that were also subsequently described by Tonan, Moers, \& Hirschberg [18]. These can range from the case of grazing flow but with zero bias flow (so that a recirculating flow occurs within the cavity formed by the orifice) through to relatively high ratios of bias to grazing flow. In this latter case the flow separates around the orifice, with the most extreme case being for zero grazing flow (i.e. the plenum fed condition). Subsequent to this, various studies have tried to relate the discharge coefficient, based on the steady state flow field of an orifice, to its acoustic resistance. For example, Sun, Jing, Zhang, \& Shi [20] undertook measurements on thin circular and rectangular orifices. The data was presented in terms of acoustic impedance and a quasi-steady 1D model was proposed that attempted to relate the discharge coefficient with acoustic resistance. In addition Tonan, Moers, \& Hirschberg [18] undertook measurements and developed a quasi-steady model based on the Bernoulli equation and integral conservation laws (mass and momentum) and again considered results in terms of a discharge coefficient (in this case expressed as a vena contraction ratio) and the real part of impedance (i.e. acoustic resistance). This was for a variety of geometries with orifice L/D ratios in excess of 1 , with the assumption being the orifice thickness results in the flow exiting the orifice normal to the perforated plate (i.e. aligned with the orifice centreline).

This paper is concerned with the quasi-steady acoustic absorption characteristics of relatively thin orifices (i.e. L/D 0.2) that would be typically used to form a perforated liner. The liner is backed by a non-resonating rigid wall to create a passage that supplies air to the liner (as typical of many engineering applications). A range of grazing to bias flow combinations $\left(U_{g} / U_{b} \sim 0.32\right.$ to 1.19$)$ is investigated. Initially the steady state characteristics of the orifices are measured and expressed in 
terms of a discharge coefficient, whilst the acoustic characteristics are mainly presented in terms of acoustic admittance. Over a prescribed operating range, of grazing to bias flow velocity ratios, a relatively simple semi-empirical model can be applied to capture the acoustic characteristics of the perforated liner configurations investigated.

\subsection{Experimental Facility}

The experimental work was carried out at nominally ambient conditions using the facility illustrated in Figure 1. In its baseline configuration this consists of two perpendicular passages, the grazing and bias flow passages along with associated centrifugal fans and loudspeakers.

Atmospheric air is drawn into the upstream settling chamber via a calibrated bell-mouth intake (that also provides a means of measuring the inlet mass flow). The air then passes into the horizontal section (grazing flow passage) of the test rig $121 \mathrm{~mm}$ (width) $\times 2300 \mathrm{~mm}$ (length) $\times 25 \mathrm{~mm}$ (height) which provides a grazing flow to the perforated liner located halfway down the passage. Air can pass through the perforated liner to enter the vertical section $(120 \mathrm{~mm} \times 120 \mathrm{~mm})$, so providing the liner bias flow, or continue along the horizontal passage to enter the downstream settling chamber. To control the amount of grazing flow passing through the horizontal section a flexible pipe is connected to the downstream settling chamber, the outlet of which is attached to a variable speed centrifugal fan. Another centrifugal speed fan is located downstream of the vertical section (lower plenum) and, in this way, the amount of flow passing through the facility can be varied along with the ratio of grazing to bias flow velocities. In addition to the baseline configuration, measurements could also be undertaken with the grazing flow passage removed. In this case the perforated liners were plenum fed, with the flow through the liner being controlled by the centrifugal fan located downstream of the vertical section.

An unsteady pressure drop is applied to the perforated liner using two JBL AL6115 600W loudspeakers that were attached to the downstream end of the bias flow passage. The loudspeakers were connected to a Chevin Research A3000 amplifier system with the excitation system being specified with the help of Biron \& Simon [21]. The loudspeakers are designed to generate plane acoustic waves that pass along the pipe towards the perforated liner. The highest frequency at which the acoustic waves remain essentially plane in the bias flow passage is approximately $1400 \mathrm{~Hz}$, with all tests being undertaken well below this frequency $(<450 \mathrm{~Hz})$. In this way the cut-on of higher modes was avoided. The settling chambers at each end of the grazing flow passage were lined with acoustic foam to absorb sound, so as to minimise the reflection of any transmitted sound back towards the liner.

Two perforated liners were used for the experimental investigations reported here (Figure 2) which utilised either plain $(\varnothing 4.0 \mathrm{~mm})$ and what will be subsequently referred to as 'skewed' $(\varnothing 4.3 \mathrm{~mm})$ orifices. These were drilled and, in the case of the skewed orifices, a further swaging process was 
applied to achieve the required geometry. Each plate incorporated a total of 28 orifices which were distributed across 5 rows to given an open area ratio of order $6 \%$. Each liner had a thickness (i.e. orifice length) of $0.8 \mathrm{~mm}$, thereby resulting in orifice L/D values of order 0.2 . The amount of holes was deliberately chosen as a compromise between the accuracy of measurement and the need to avoid significant effects associated with the transmission of energy through the holes (rather than absorption).

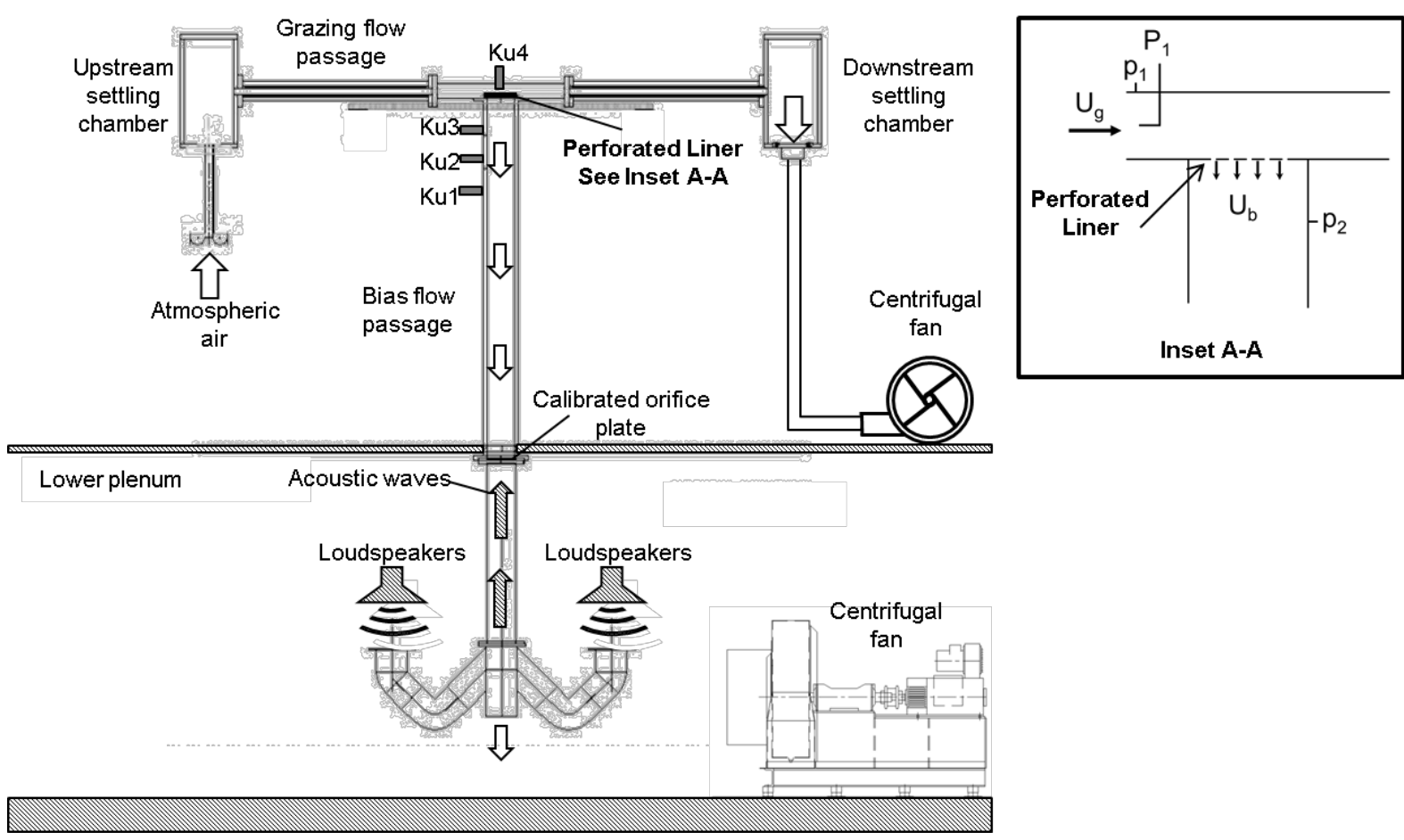

Figure 1 Schematic of test rig incorporated within the low intensity noise facility.

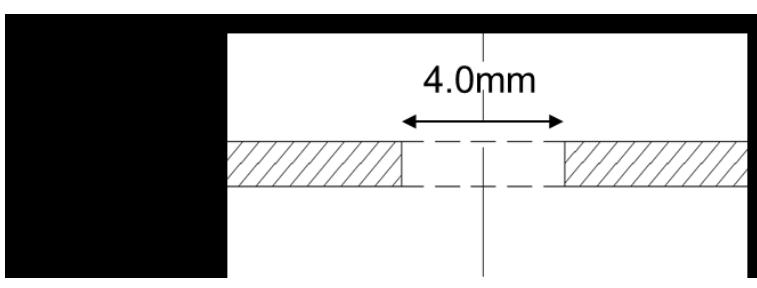

(a) Plain holes with $\varnothing=4 \mathrm{~mm}$
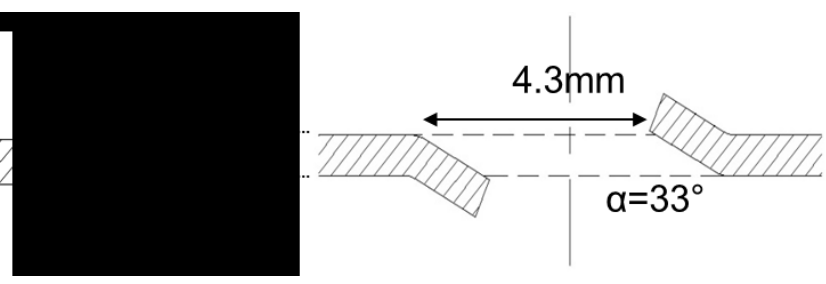

(b) Skewed holes with $\varnothing=4.3 \mathrm{~mm}$

Figure 2 Geometries of perforated liner test plates (i) plain liner and (ii) skewed liner.

\subsection{Steady State Measurements:}

In this configuration the loudspeakers were not activated and a calibrated orifice plate was inserted into the bias flow passage as shown Figure 1. A pitot probe was also located in the grazing flow passage at mid height, some 6 passage heights upstream of the perforated liner, along with an 
associated static pressure tapping to enable measurement of the local dynamic head $\left(P_{1}-p_{1}\right)$. This enabled the grazing flow velocity, $U_{g}$, to be determined. Similarly, a static pressure measurement downstream of the perforated liner (1 passage height) provided a measurement of the liner pressure drop $\left(P_{1}-p_{2}\right)$. This enabled the jet velocity, $U_{j}$ at the vena contracta to be determined (i.e. $\left.P_{1}-p_{2}=1 / 2 \rho U_{j}^{2}\right)$. The mass flow passing through the liner was obtained via measurement across the downstream orifice plate. Hence, based on the geometric area of the liner orifices the bias flow velocity, $U_{b}$ could be derived, Figure 3 .

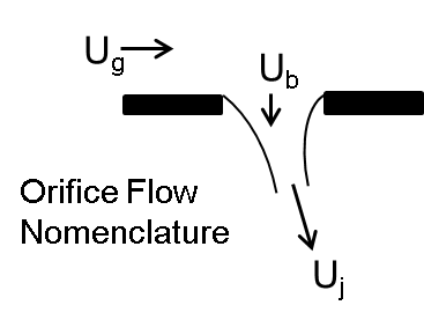

Figure 3 Orifice flow nomenclature defining grazing $\left(U_{g}\right)$, bias $\left(U_{b}\right)$ and jet velocities $\left(U_{j}\right)$.

\subsection{Unsteady Measurements:}

For these measurements the orifice plate was removed and the loudspeakers activated over a range of frequencies. Up to 3 fast response Kulite pressure transducers were located in the vertical passage downstream of the liner, from which the magnitude of the incident/reflected plain acoustic waves in the passage could be determined (see section 3). For some measurements a fast response pressure transducers was also placed in the grazing flow passage, as shown in Figure 1 above. The ratio of grazing to bias flow mean velocities was determined by the total and static pressure measurements upstream and downstream of the perforated liner.

A further consideration is the boundary condition upstream of the perforated liner and the assumption of zero pressure perturbation $(\hat{p}(u s) \sim 0)$. For a plenum fed configuration an impedance value is typically derived from only the downstream side unsteady pressure and will therefore include both an orifice and radiation impedance (i.e. the latter being associated with the sound radiated from the orifice). However, the reactive part of the radiation impedance is included in the orifice impedance. This is because it represents the effects of the inertial mass of the local air motion in the immediate vicinity of the orifice (and hence is included via an 'end' correction). The radiation resistance will also be included in the measurements, with the acoustic pressure upstream of the liner $(\hat{p}(u s))$ equating to the radiation pressure. For a plenum fed boundary condition this equates to a piston which has a radiation resistance equivalent to $k R^{2} / 4$ (as described by Cummings \& Eversham [22]). This is of a magnitude that is several orders of magnitude less than the measured liner resistance and is therefore negligible $(\hat{p}(u s) \sim 0)$. Hence 


$$
\frac{K_{R}}{2 R}=-\frac{i \omega \rho \hat{Q}}{\hat{p}(d s)} \text { and } Z=\frac{\hat{p}(d s)}{\hat{u}_{b}}
$$

For the majority of measurements reported the conditions upstream of the perforated liner are not well defined due to the presence of the grazing flow passage. With this in mind example admittance data is presented for a perforated liner subjected to a range of operating condition, Figure 4. At approximately $550 \mathrm{~Hz}$ significant changes in the admittance values are observed due to the cut-on of an axial mode within the grazing flow such that $(\hat{p}(\mathrm{us}) \neq 0$ ). Hence all measurements were obtained at frequencies below $550 \mathrm{~Hz}$ (i.e. $450 \mathrm{~Hz}$ or less). In addition, measurements of the unsteady pressure within the grazing flow passage, opposite to the perforated liner, were used to confirm negligible unsteady pressure fluctuations upstream of the liner orifices ( $\hat{p}(\mathrm{us}) \sim 0$ ).

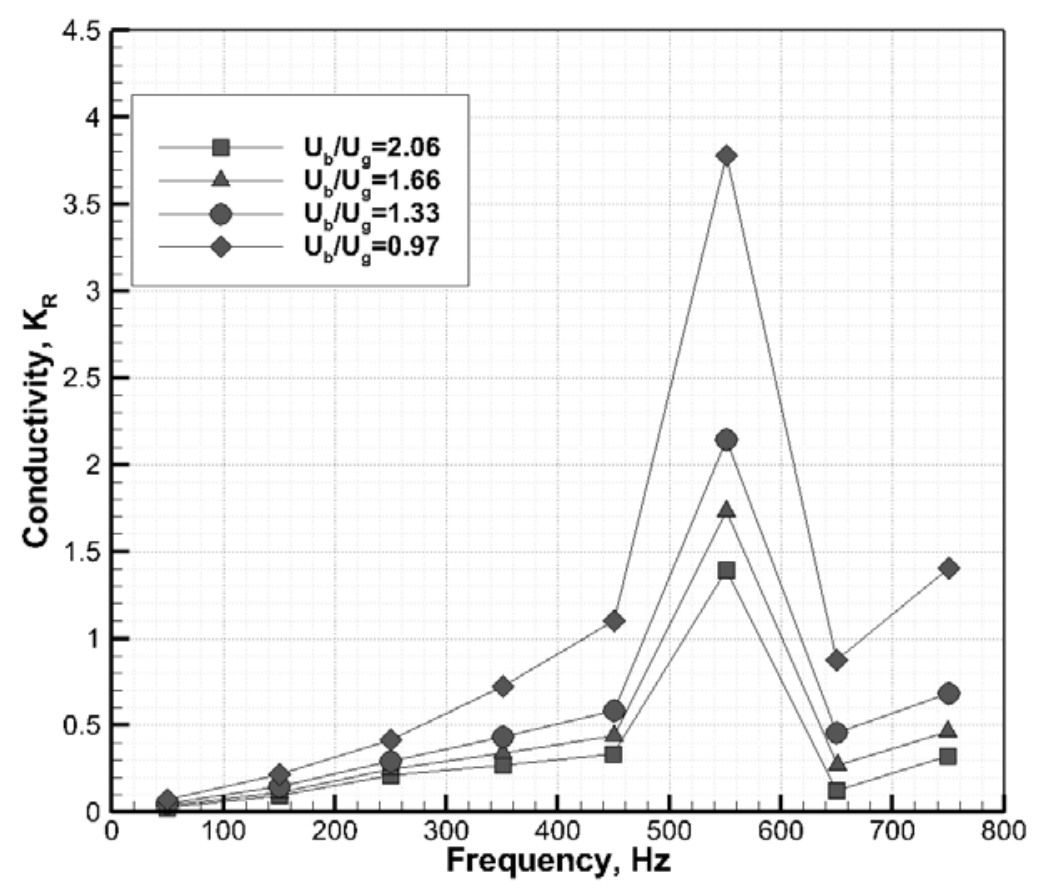

Figure 4 Example admittance data and axial mode cut-on within grazing flow passage.

\section{0}

Data Reduction and Experimental Errors

For the steady state measurements the discharge coefficient is defined as the measured to ideal mass flow through the liner i.e.

$$
C_{d}=\frac{m_{\text {meas }}}{\rho A_{h} \sqrt{\left(\frac{2}{\rho}\left(P_{1}-p_{2}\right)\right)}}=\frac{m_{\text {meas }}}{\rho A_{h} U_{j}}
$$


The unsteady pressure drop and volume flow through the orifice specific impedance of the injector was obtained using the multi-microphone technique whose underlying principle was described by Seybert \& Ross [23]. At any point in the duct, the acoustic pressure can be expressed as a superposition of the incident (i.e. travelling upstream and towards the orifice) and reflected (i.e. travelling away from the orifice) waves:

$$
\hat{p} e^{i \omega t}=\hat{p}_{i} e^{i \omega t i k_{-} x}+\hat{p}_{r} e^{i \omega t-i k_{+} x}
$$

where $\omega$ is the angular frequency of the waves and the subscripts ' $i$ ' and ' $r$ ' denote the incident and reflected waves respectively. The wave numbers are $k \pm=\omega /(U \pm c)$ in which $c$ is the speed of sound and $U$ is the mean velocity of the bias flow within the duct. Accordingly, the acoustic velocity at any point in the duct can be found as:

$$
u_{d u c t}^{\prime}=\hat{u} e^{i \omega t}=\frac{-\hat{p}_{i} e^{i \omega t i k_{-} x}+\hat{p}_{r} e^{i \omega t-i k_{+} x}}{\rho c}
$$

where $\rho$ is the air density in the duct. The Mach number of the flows considered in this work is less than 0.2 and the Helmholtz number, $H_{n}=k \cdot 2 \mathrm{R}$ (where $\mathrm{R}$ is the radius of the orifice), is less than 0.04. Under these conditions the variation of density around the orifice is insignificant and the flows could be in general treated as incompressible.

Pressure signals measured simultaneously at two different axial locations are sufficient to reconstruct the incident and reflected pressure waves. However, the accuracy is shown to be sensitive to the locations of the two sensors relative to the mode shape of the pressure wave in the duct (which changes with frequency). This problem can be mitigated by taking measurements at more axial locations. In this paper, four transducers were used in order to obtain reliable data over the frequency range studied. The averaged complex amplitudes described in the previous section form the following linear equation system:

$$
\left[\begin{array}{cc}
e^{i k_{-} x_{1}} & e^{-i k_{+} x_{1}} \\
\vdots & \vdots \\
e^{i k_{-} x_{4}} & e^{-i k_{+} x_{4}}
\end{array}\right]\left[\begin{array}{c}
\hat{p}_{i} \\
\hat{p}_{r}
\end{array}\right]=\left[\begin{array}{c}
\hat{p}_{1} \\
\vdots \\
\hat{p}_{4}
\end{array}\right]
$$

where $x_{1}$ to $x_{4}$ are the axial locations of the Kulites. This over-determined system was solved with the least square method. The acoustic velocity in the duct at the liner can then be calculated from Eq. (7) by inserting the appropriate axial location. To find the acoustic velocity for the liner the relation $u_{b}^{\prime} A_{\text {liner }}=u_{\text {duct }}^{\prime} A_{\text {duct }}$ is applied where $A_{\text {duct }}$ is the area of the bias flow passage. In this way the unsteady volume flow through the liner can be determined. As described by Rupp [6] wave amplitudes and phase angles (pressure and velocity) were measured to less than $3 \%$ and $0.5 \%$ error, with repeatability better than $1 \%$. 


\subsection{Steady State Flow Field}

For the case of a pure grazing flow Kooijman, Hirschberg, \& Golliard [24] investigated the potential effect of the grazing flow boundary layer approaching various orifice shapes. Hence, for completeness the velocity profile upstream of the test section is presented, Figure 5 . Over the range of operating conditions investigated this profile remained relatively invariant and, as expected, boundary layers are evident adjacent to each surface. Note that $x=0.0 \mathrm{~mm}$ corresponds to the passage wall in which the perforated liner is located (some 6 passage height diameters downstream). Over the range of operating conditions investigated this profile remained relatively invariant. At this location the total pressure was monitored at mid-height along with the static pressure from which the grazing velocity $\left(U_{g}\right)$ was derived. This was assumed to represent the free-stream (or boundary layer edge) velocity and is the same approach as that used by other researchers in this area. A grazing flow velocity based on a bulk average (derived from the passage mass flow) would provide a value that is approximately $90 \%$ of the mid-height value. This reference total pressure was also used to derive the orifice discharge coefficients.

The amount of flow passing through the liner, relative to the approach flow, is a function of the bias to grazing flow velocity ratio. Hence this can range from a relatively small flow (at the lowest bias to grazing flow velocity ratio tested) up to a maximum value associated with the highest ratio condition. At the highest velocity ratio tested, approximately $26 \%$ of the grazing passage flow passed through the perforated liner, with the remaining flow continuing along the passage.

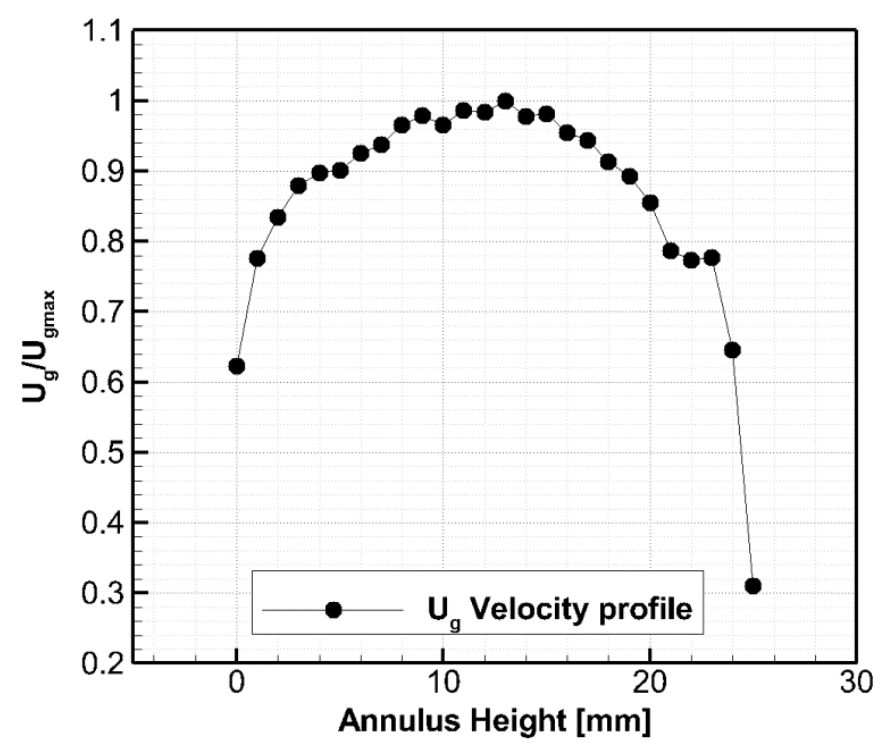

Figure 5 Grazing flow annulus velocity profile.

For the plane orifice liner the measured discharge coefficients are presented in terms of (a) bias to grazing flow ratios and (b) jet to grazing flow velocity ratios for which data was acquired, Figure 6 . As 
already defined the bias flow velocity refers to that in the plain of the orifices (based on the measured mass flow and geometric orifice areas) whilst the jet-flow velocity refers to that at the downstream vena contracta (based on the liner pressure drop). As expected for the plain orifices the discharge coefficient increases from approximately 0.25 (at the lowest bias to grazing flow ratio tested) to 0.65 (for the highest ratio tested). In addition, at the lowest and highest ratio conditions tests were also performed in which the same velocity ratio was maintained but the absolute pressures were doubled and halved relative to the datum. It can be seen that, within experimental error, the same discharge coefficients were obtained, Figure 7. Hence, the steady state flow field through each orifice is only dependent on the bias to grazing flow velocity ratio (as suggested by several authors including, for example, Sun, Jing, Zhang, \& Shi [20]). A final test was conducted in which the grazing flow (and the associated grazing flow passage) was completely removed. In this case the liner is plenum fed (i.e. zero grazing flow and hence an infinite jet to grazing flow velocity) for which the measured discharge coefficient was 0.72 . This is thought consistent with the trends observed with grazing flow present (i.e. the value tending towards 0.72 at high bias to grazing flow ratios).

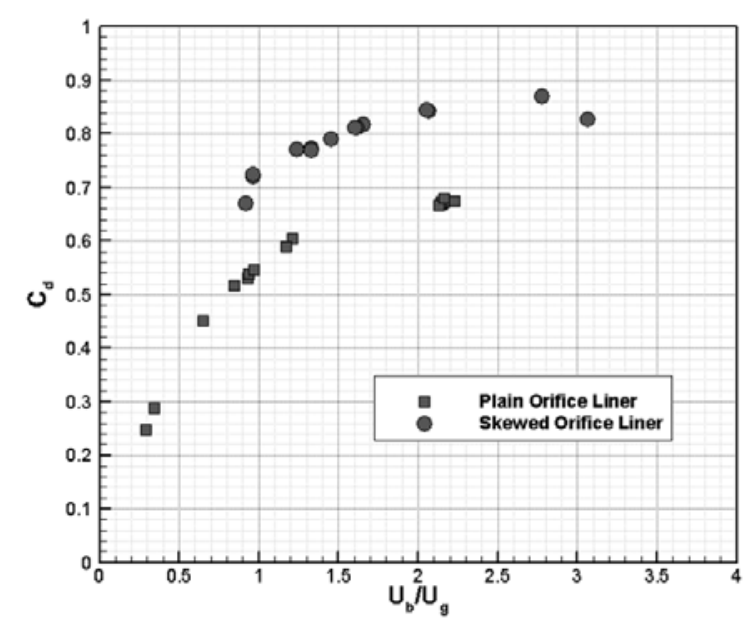

(a)

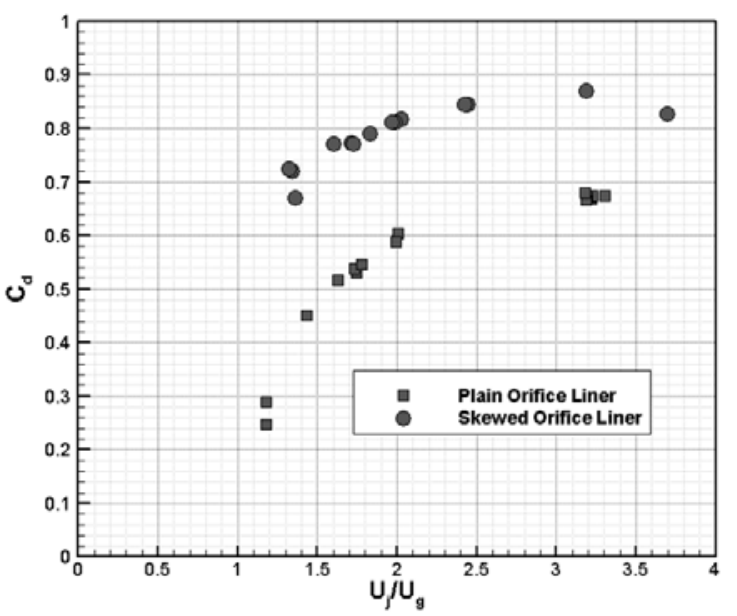

(b)

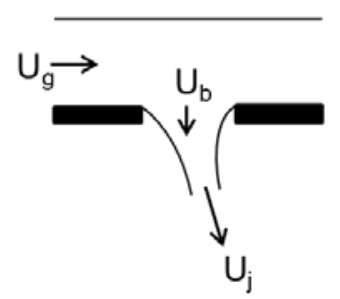

$$
\begin{gathered}
P_{1}-p_{2}=\frac{1}{2} \rho U_{j}^{2} \\
C_{d}=\frac{m_{\text {meas }}}{\rho A_{h} U_{j}}
\end{gathered}
$$

\section{Figure 6 Discharge coefficient, $C_{d}$ vs velocity ratio (a) $U_{b} / U_{g}$ and $(b) U_{j} / U_{g}$.}

A similar data set is also presented for the skewed orifice liner but, in this case, the sensitivity to the ratio of grazing flow to jet velocity is reduced. This is to be expected since the modified geometry is designed to minimise flow separation from around each orifice as the flow passes through the liner. Hence for the lowest ratio the discharge coefficient was approximately 0.67 and increased to 0.85 at 
the highest velocity ratio condition. Tests were also conducted with the grazing flow passage removed (i.e. plenum fed). In this case a discharge coefficient of 0.87 was obtained for the skewed orifice liner.

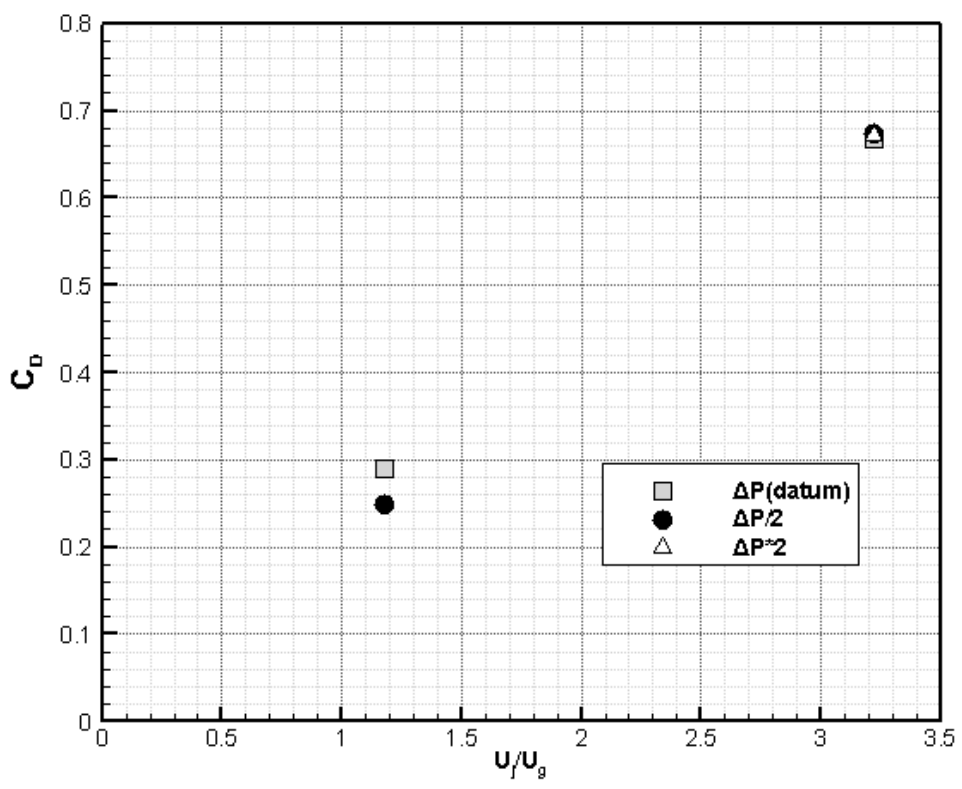

Figure 7 Discharge coefficient, $C_{d}$ invariant when pressure drops doubled or halved but the velocity ratio is maintained constant.

For a given geometry the variation of discharge coefficient is a function of the bias to grazing flow velocity ratio $\left(U_{b} / U_{g}\right)$. For a plenum fed hole the upstream total pressure, together with the downstream static pressure, gives rise to a dynamic head and associated jet velocity at the vena contracta $\left(P-p=\frac{1}{2} \rho U_{j(p)}{ }^{2}\right)$. With the introduction of grazing flow the upstream total pressure must be increased to obtain the same flow rate through the hole such that $\left(P_{g}-p=\frac{1}{2} \rho U_{j}{ }^{2}\right)$. As a first order approximation this increase in pressure is assumed to be due to the introduction of the grazing flow and its associated dynamic head $\left(P_{g}-P=\frac{1}{2} \rho U_{g}^{2}\right)$ then.

$$
\left(\frac{U_{b}}{U_{g}}\right)^{2}=\frac{\left(C_{d}^{2}\right)\left(C_{d(p)}^{2}\right)}{C_{d(p)}^{2}-C_{d}^{2}}
$$

This is equivalent to assuming that the grazing flow momentum is maintained as it passes through the orifice such that the jet velocity $\left(U_{j}\right)$, relative to the plenum condition, now has an additional component $\left(\sim U_{g}\right)$ as shown in Figure 6 . For a thin liner this is thought to be a reasonable approximation. Hence for the plain liner the measured discharge coefficient for the plenum fed condition has been used $\left(C_{d(p)}\right)$, together with Eq. (9), to predict the variation of hole discharge coefficient over the range of velocity ratios tested. It can be seen that, to first order, reasonable agreement is obtained between the measured and predicted values, Figure 8 . However, for the 
skewed orifice liner the agreement is not so good with the experimental values being greater than those predicted. To some extent this is to be expected, since the skewed orifice geometry will help deflect the flow as it passes through. It is therefore to be expected that the measured values will be in excess of those predicted by Eq. (9).

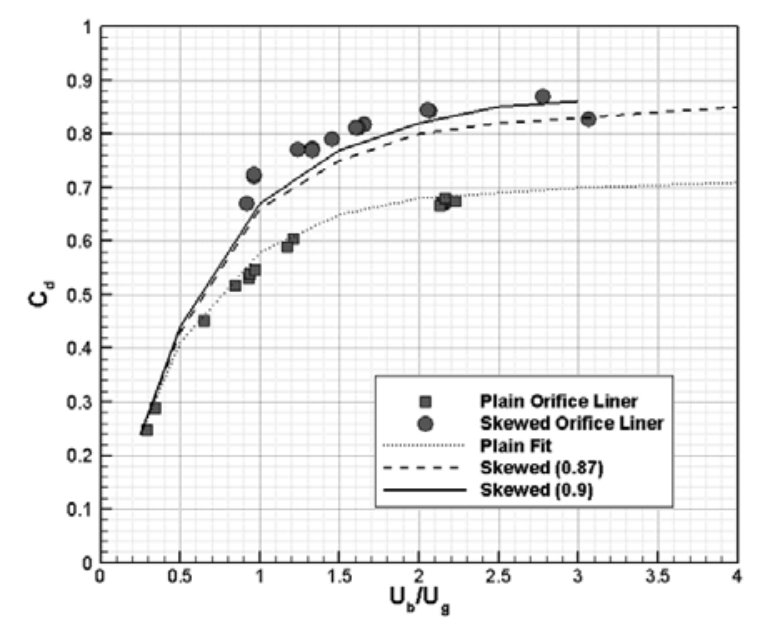

(a)

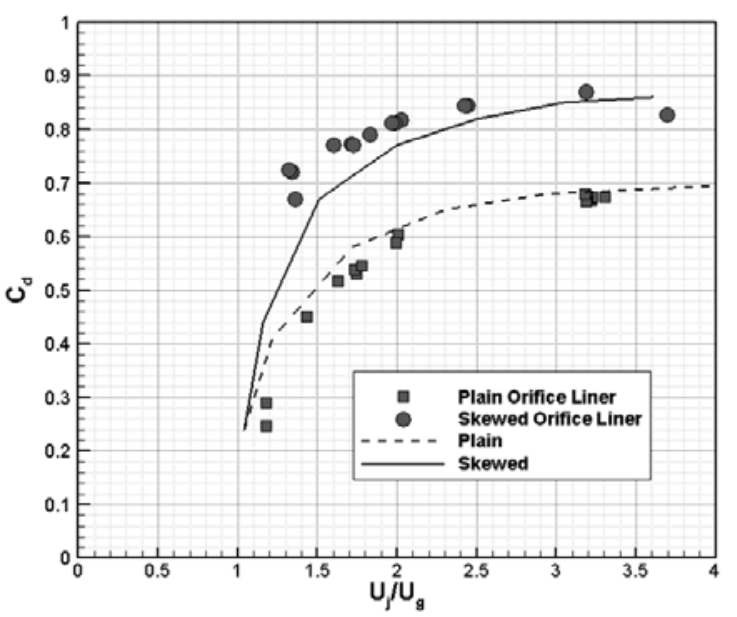

(b)


Figure 8 Discharge coefficient, $C_{d}$ vs velocity ratio (measured vs Eq. (9)) (a) $U_{b} / U_{g}$ and $(b) U_{j} / U_{g}$.

\subsection{Acoustic Conductivity and Impedance}

\subsection{Plenum fed}

The impedance or conductivity of a plenum fed hole (i.e. zero grazing flow) has been documented by several authors including Rupp [6]. Note that the impedance based on the duct side unsteady pressure will include both the orifice and radiation impedance (i.e. the latter being associated with the sound radiated from the orifice). However the reactive part of the radiation impedance is included in the orifice impedance. As already stated this is because it represents the effects of the inertial mass of the local air motion in the immediate vicinity of the orifice (and hence is included via the 'end' correction). The radiation resistance will also be included in the measurements, with the acoustic pressure upstream of the liner $(\hat{p}(u s))$ equating to the radiation pressure. For a plenum fed boundary condition this equates to a piston which has a radiation resistance equivalent to $k R^{2} / 4$ (as 
described by Cummings \& Eversham [22]). This is of a magnitude that is several orders of magnitude less than the measured liner resistance and is therefore negligible $(\hat{p}(u s) \sim 0)$. Hence

$$
Z=\frac{\hat{p}(u s)-\hat{p}(d s)}{\hat{u}_{b}}=-\frac{\hat{p}(d s)}{\hat{u}_{b}}
$$

Using the linearized Bernoulli equation between the orifice and the downstream vena contracta then:

$$
p^{\prime}(d s)=\rho U_{j} u_{j}^{\prime}
$$

and the effective discharge coefficient is

$$
C_{d(p)}=\frac{U_{b}}{U_{j}}=\frac{u_{b}^{\prime}}{u_{j}^{\prime}}
$$

The conductivity is given by

$$
K_{R}=-\frac{i \omega \rho \hat{Q}}{\hat{p}(d s)}=-\frac{i \omega \rho \pi R^{2} \hat{u}_{b}}{\widehat{p}(d s)}=2 R(\Gamma-i \delta)
$$

where for quasi steady flow $\Gamma^{\sim} 0$ so that

$$
\delta_{q s}=\frac{\pi}{2} \frac{\omega R}{U_{b}} C_{d(p)}^{2}=\frac{\pi}{2} S t C_{d(p)}^{2}
$$

For plenum fed conditions a discharge coefficient can be estimated by measuring the admittance over a range of frequencies. As will be subsequently indicated this results in values of approximately 0.67 (plain) and 0.85 (skewed). These results compare reasonably well with the values of 0.72 (plain) and 0.87 (skewed) estimated from the steady state flow field (i.e. the measured mass flow and orifice pressure drop).

\subsection{With Grazing Flow}

Some example measurements are presented for a perforated plate incorporating plain holes operating at a bias to grazing flow velocity ratio of 2.1, Figure 9. The data was obtained both at a 
datum operating condition, and one in which the pressure drops were doubled (but the velocity ratio, $U_{b} / U_{g}$ was maintained constant). The data is presented both in terms of the derived impedance and conductivity. Initially the data is plotted against frequency but, using the steady state discharge coefficient values, the data is presented in terms of Strouhal number (based on the bias flow velocity through the orifice), Figure 10. For the resistive part of the impedance different values are obtained for the 2 operating conditions. However, this is to be expected since this reflects the different mean velocities passing through the perforated liner $\left(\operatorname{Re}(Z) \sim \rho U_{b}\right)$. When expressed relative to Strouhal number it can be seen the admittance collapses onto a single curve for both operating conditions. In addition, the paper is concerned with the quasi steady response (i.e. where any inertial effects are small). The presented data indicates that, over the range of frequencies being investigated, the measured inertia $(\Gamma)$ terms are relatively small.

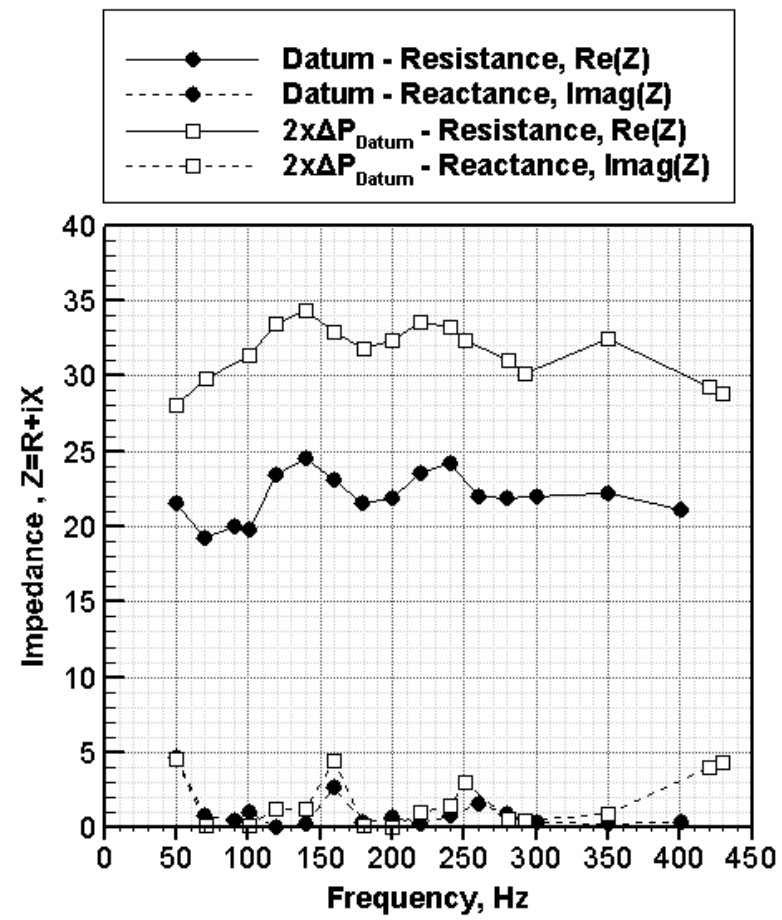

(a)

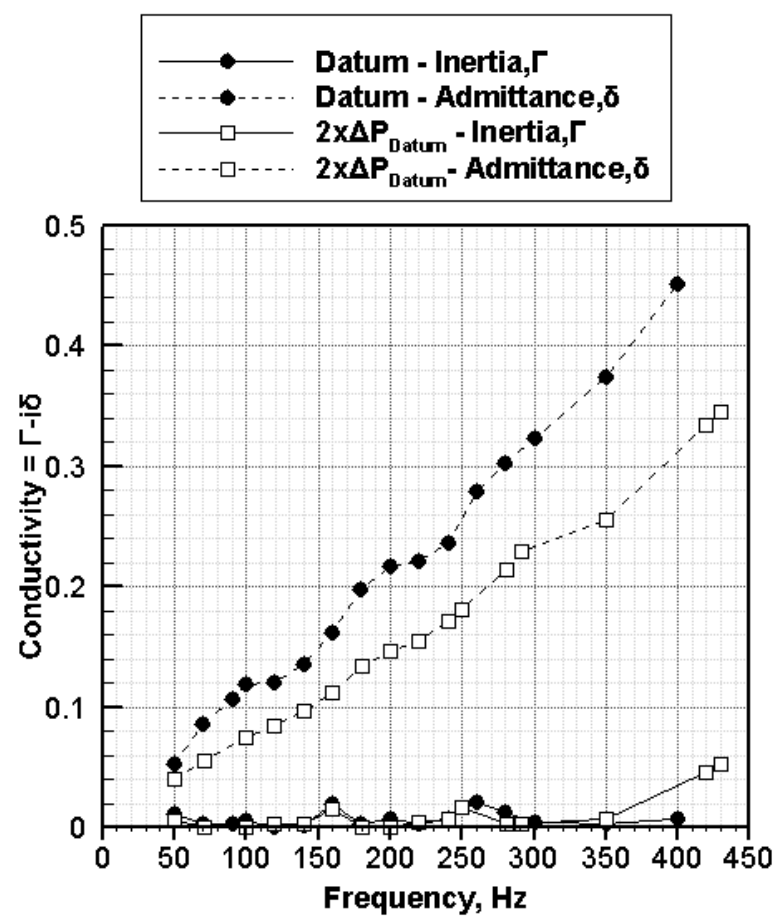

(b)

Figure 9 Figures showing plots of components (a) impedance (Resistance and Reactance) and (b) conductivity (Inertia and Admittance) vs frequency. 


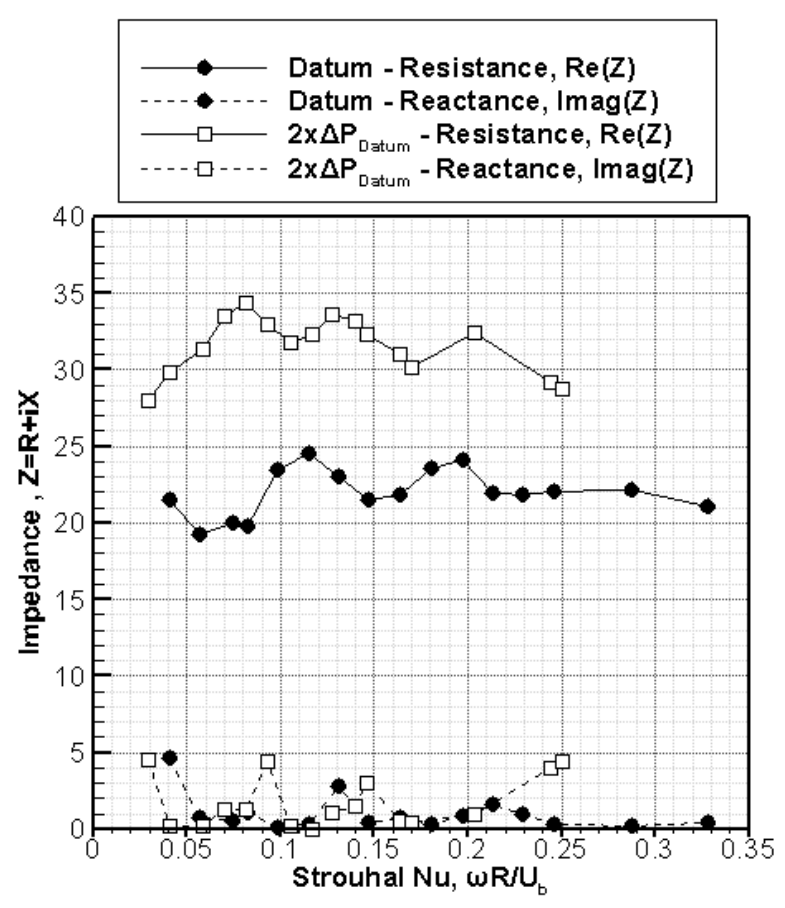

(a)

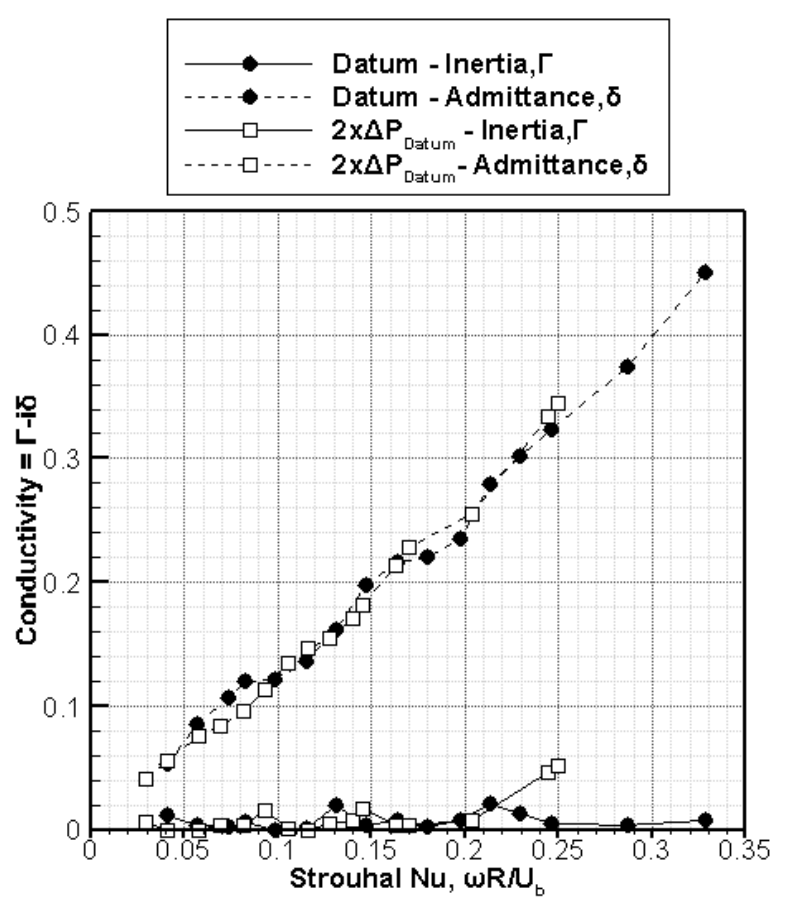

(b)

Figure 10 Figures showing plots of components (a) impedance (Resistance and Reactance) and (b) conductivity (Inertia and Admittance) vs Strouhal number.

\subsubsection{Admittance}

The admittance values measured for the perforated liner incorporating plain orifices is presented for a range of bias to grazing flow ratios Figure 11. It might be assumed that, following on from the expression for a plenum fed hole (Eq. (9)), the admittance may correlate with the measured discharge coefficient values (solid black line in Figure 9 ) associated with a particular velocity ratio but this is clearly not the case (i.e. $\delta \neq \frac{\pi}{2} S t C_{d}^{2}$ ). Instead it appears the admittance values are comparable for most of the velocity ratios tested and, as will be subsequently discussed, is equivalent to that of a plenum fed liner (i.e. $\delta_{q s}=\frac{\pi}{2} S t C_{d(p)}^{2}$ ). Figure 12 shows results of the measured admittance for the plain orifice liner which are comparable for the different velocity ratios. The exception to this is data obtained at the very lowest bias to grazing velocity ratio tested $\left(U_{b} / U_{g}<0.64\right)$. As the bias to grazing velocity ratio is decreased then eventually the flow passing through the orifice must impinge on, and interact with, the trailing edge of the orifice. Hence, it is thought likely this is the reason for the change in the admittance characteristics at this low velocity ratio. Data is also presented for the perforated liner that incorporated skewed orifices (Figure 13 and Figure 14) with generally similar characteristics being observed. However, in this case for all the velocity ratios tested the admittance value corresponded to that measured for the plenum fed 
condition at the same Strouhal number. A comparison of the different liner results for the same velocity ratios measured is also included (Figure 15).

Strictly speaking the presented data was not all captured in the linear operating regime whereby the mean velocity, through the liner orifices, was much greater than the unsteady velocity (i.e. $U_{b} \gg$ $u_{b}^{\prime}$ ). In many cases the acoustic pressure drop was of sufficient magnitude so that the unsteady velocity approached that of the mean orifice velocities (i.e. $U_{b} \geq u_{b}^{\prime}$ ) with operation thereby potentially in the non-linear regime. However, despite this no significant change in the acoustic characteristics were observed (e.g. Figure 4). This is consistent with that of Luong, Howe, \& McGowan [5] who, although considering the case of a plenum fed hole only, indicated that nonlinearity has a negligible influence on conductivity assuming flow reversal does not occur. However at low bias flows or higher levels of acoustic excitation (i.e. $U_{b}<u^{\prime}{ }_{b}$ ), such that reverse flow does occur, the inflow to each liner orifice may be affected. Further work would therefore be required to establish if these characteristics were also observed at these conditions where reverse flow is present.

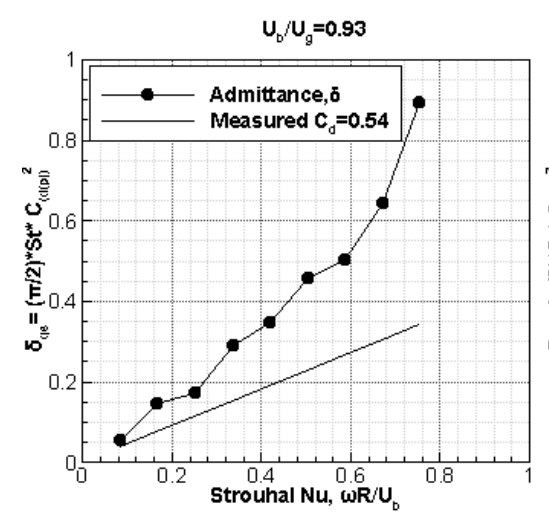

(a) $\frac{U_{b}}{U_{g}}=0.93$



(b) $\frac{U_{b}}{U_{g}}=1.17$

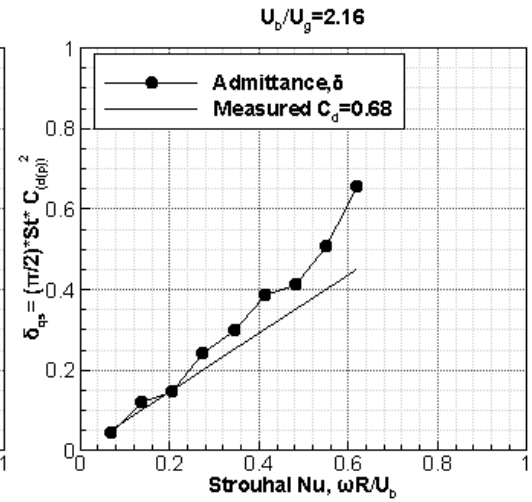

(c) $\frac{U_{b}}{U_{g}}=2.16$

Figure 11 Figures showing admittance values measured for (a) $\frac{U_{b}}{U_{g}}=0.93$, (b) $\frac{U_{b}}{U_{g}}=1.17$ and (c) $\frac{U_{b}}{U_{g}}=2.16$ for the plain orifice liner. 


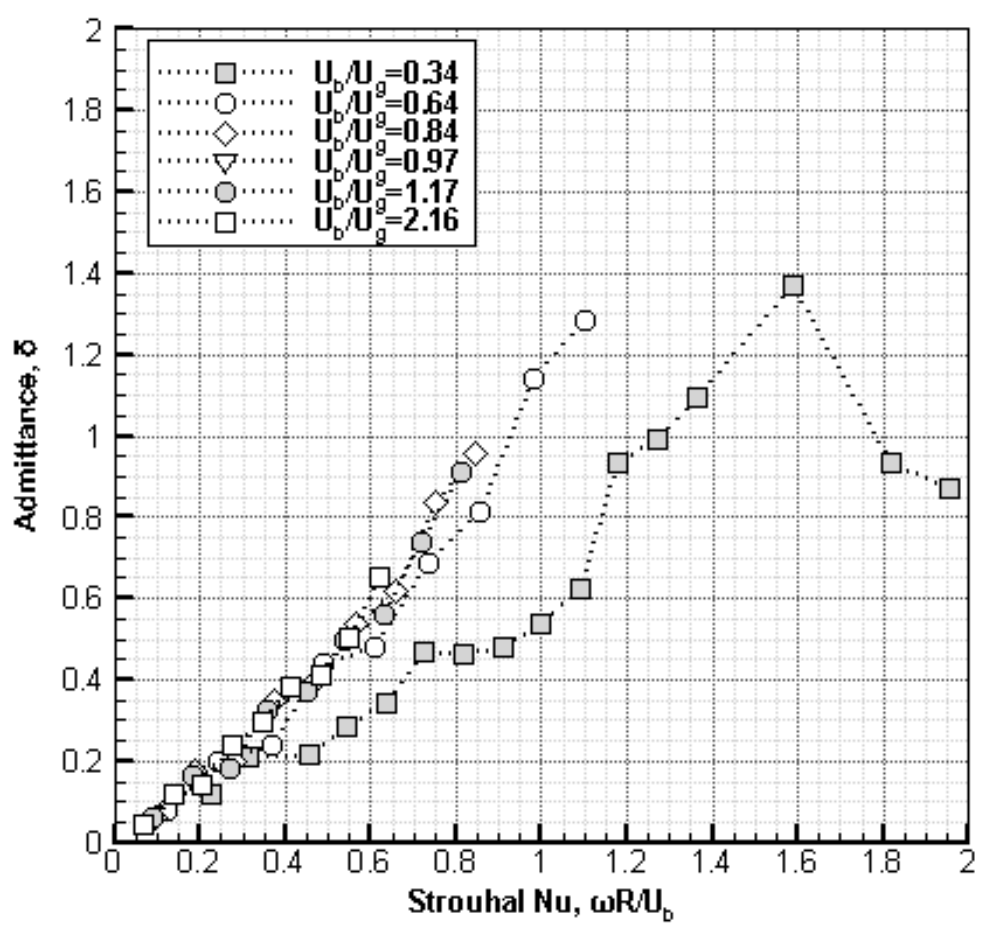

Figure 12 Figure showing summary of admittance values measured for a range of $\mathbf{U}_{\mathbf{b}} / \mathbf{U}_{\mathrm{g}}$ ratios for plain orifice liner. For $\mathbf{U}_{b} / \mathbf{U}_{\mathbf{g}} \geq \mathbf{0 . 6 4}$, the admittance values are comparable.

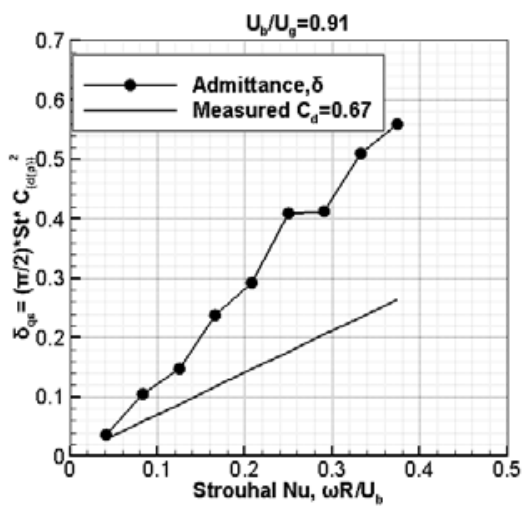

(a) $\frac{U_{b}}{U_{g}}=0.91$

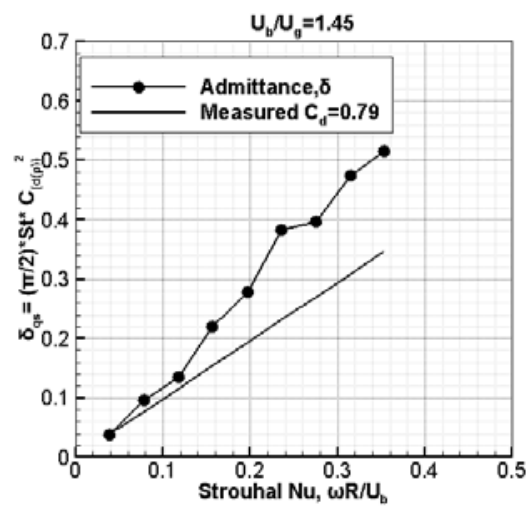

(b) $\frac{U_{b}}{U_{g}}=\mathbf{1 . 4 5}$

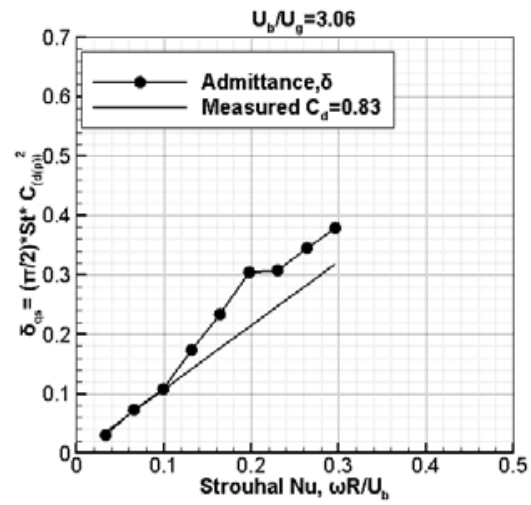

(a) $\frac{U_{b}}{U_{g}}=3.06$

Figure 13 Figures showing admittance values measured for (a) $\frac{U_{b}}{U_{g}}=0.91$, (b) $\frac{U_{b}}{U_{g}}=1.45$ and (c) $\frac{U_{b}}{U_{g}}=3.06$ for the skewed orifice liner. 




Figure 14 Figure showing summary of admittance values measured for a range of $\mathbf{U}_{b} / \mathbf{U}_{g}$ ratios for skewed orifice liner.

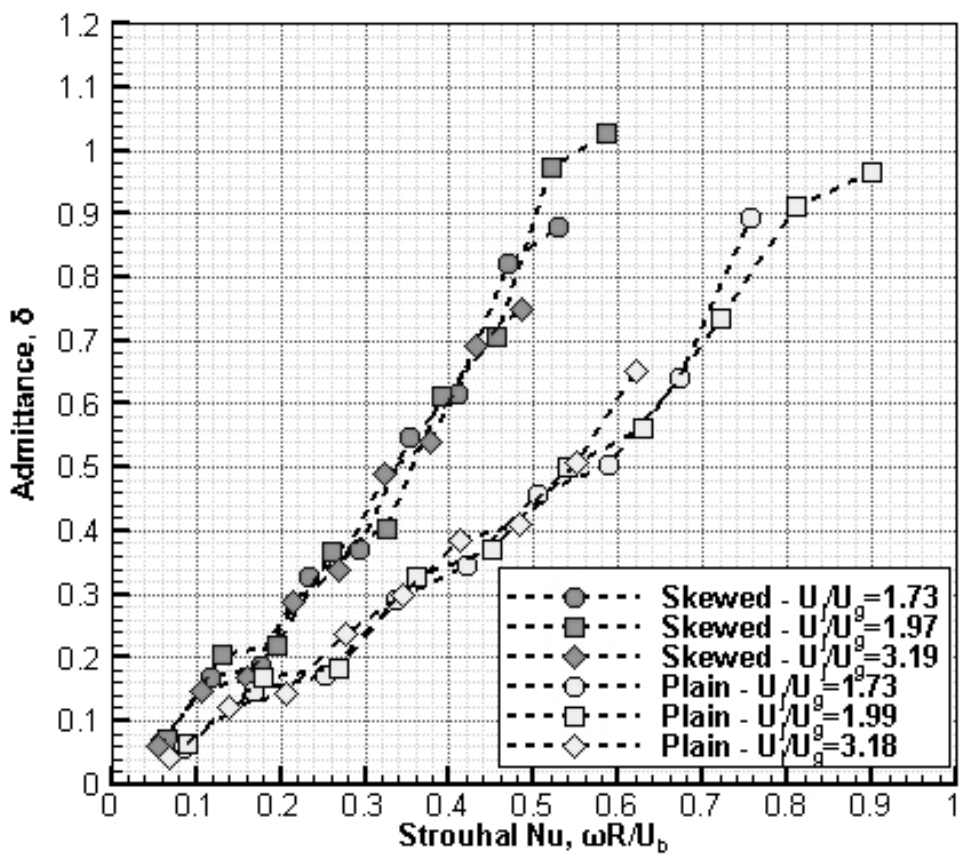

Figure 15 Comparison of the measured plain and skewed liner results for nominally the same velocity ratios. 


\subsection{Quasi-Steady Flow Field Characteristics}

It appears that over most of the operating conditions investigated, the presence of grazing flow has negligible effect on the acoustic admittance of the perforated liner. For skewed holes no differences were observed over the range of bias to grazing velocity ratios investigated, whereas with plain holes differences were only apparent at the lowest velocity ratios tested (i.e. $U_{b} / U_{g} \leq 0.64$ ). These observations are in broad agreement with the results from several other investigations (e.g. Sun, Jing, Zhang, \& Shi [20]). However, whereas most authors have noted this phenomenon, explanations have been limited as to why these characteristics are observed.

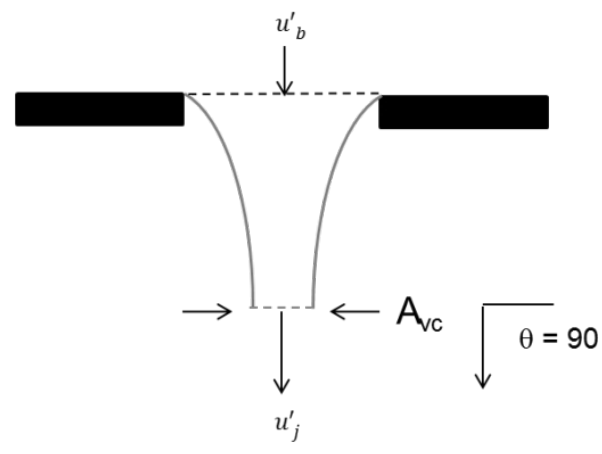

$$
Q^{\prime}=A_{v c(p)} u_{j(p)}^{\prime}
$$

$$
C_{d(p)}=\frac{A_{v c(p)}}{A_{h}}=\frac{U_{b(p)}}{U_{j(p)}}=\frac{u_{b(p)}^{\prime}}{u_{j(p)}^{\prime}}
$$

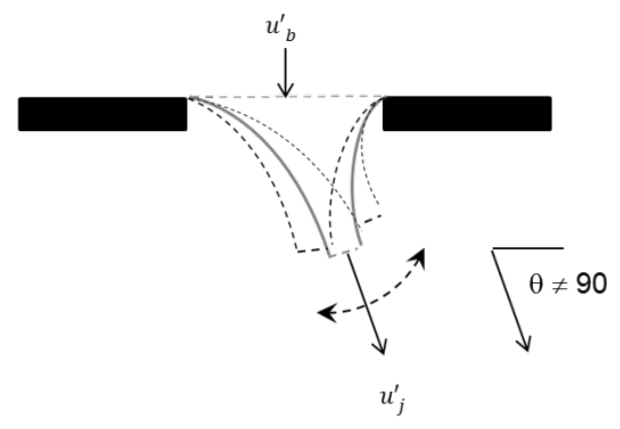

$$
Q^{\prime} \sim A_{v c} u_{j}^{\prime}+A_{v c}^{\prime} U_{j}
$$$$
C_{d}=\frac{A_{v c}}{A_{h}}=\frac{U_{b(p)}}{U_{j(p)}} \neq \frac{u_{b}^{\prime}}{u_{j}^{\prime}}
$$

Figure 16 Schematic of flow through perforated liner.

For a plenum fed hole the velocities will increase and decrease during an acoustic cycle, but the area of the vena contracta will remain constant. In other words the non-dimensional flow field remains the same (Figure 16) and several authors have tried to apply this concept in the presence of grazing flow. However, the addition of grazing flow means that the fluid issuing from the orifice does so at an angle that is no longer normal to the liner (i.e. $\theta \neq 90^{\circ}$ ). As the mean grazing flow velocity is increased, relative to that of the bias flow, so the angle of the jet decreases. As already indicated by the steady state flow field data, this results in a decrease in the area of the vena contracta and a corresponding reduction in discharge coefficient. For quasi-steady flow during an acoustic cycle it is therefore argued that (i) the inclination of the jet must vary and hence (ii) the area of the vena contracta must also change. This differs from that suggested by previous authors (e.g. Sun, Jing, Zhang, \& Shi [20]). Thus

\section{Plenum Fed:}




$$
Q+Q^{\prime}=A_{v c(p)}\left(U_{j}+u_{j(p)}^{\prime}\right)
$$

So

$$
Q^{\prime}=A_{v c(p)} u_{j(p)}^{\prime}
$$

Hence,

$$
C_{d(p)}=\frac{A_{v c(p)}}{A_{h}}=\frac{U_{b(p)}}{U_{j(p)}}=\frac{u_{b(p)}^{\prime}}{u_{j(p)}^{\prime}}
$$

With grazing flow:

$$
Q+Q^{\prime}=\left(A_{v c}+A_{v c}^{\prime}\right)\left(U_{j}+u_{j}^{\prime}\right)
$$

so

$$
Q^{\prime} \cong\left(A_{v c} u_{j}^{\prime}+A_{v c}^{\prime} U_{j}\right)
$$

Hence,

$$
C_{d}=\frac{A_{v c}}{A_{h}}=\frac{U_{b}}{U_{j}}\left(\neq \frac{u_{b}^{\prime}}{u_{j}^{\prime}}\right)
$$

The results presented in Figure 15 indicate that for a given Strouhal number (i.e. hole geometry, frequency and mean bias velocity) the same admittance is measured whether the hole is plenum fed or subjected to a grazing flow. For a given incident pressure magnitude $\left(p^{\prime}\right)$ the unsteady volume flow through the orifice $\left(Q^{\prime}\right)$ is therefore the same: 


$$
Q^{\prime}=u_{b(p)}^{\prime} A_{h}=u_{b}^{\prime} A_{h}=u_{j}^{\prime} A_{v c}+A_{v c}^{\prime} U_{j}
$$

Rearranging yields

$$
\frac{A^{\prime}{ }_{v c}}{A_{v c}}=\frac{C_{d(p)} u_{j}^{\prime}-C_{d} u_{j}^{\prime}}{C_{d} U_{j}}
$$

and since

$$
\widehat{p}=\rho U_{j(p)} u_{j(p)}^{\prime}=\rho U_{j} u_{j}^{\prime}
$$

then:

$$
\frac{A_{v c}^{\prime}}{A_{v c}}=\frac{u_{j}^{\prime}}{U_{j}}\left(\frac{C_{d(p)}^{2}-C_{d}^{2}}{C_{d}^{2}}\right)
$$

Hence this expresses the change in area of the vena contracta during an acoustic cycle as a proportion of the mean value $\left(A^{\prime}{ }_{v c} / A_{v c}\right)$, and is a function of the mean and unsteady velocity conditions at the vena contracta $\left(u_{j}^{\prime} / U_{j}\right)$, along with the hole discharge coefficients. This includes the discharge coefficient associated with that particular operating condition along with the value obtained when the liner is plenum fed. Note that with no grazing flow present the discharge coefficient corresponds to the plenum value $\left(C_{d(p)}=C_{d}\right)$ and so no change in area is observed $\left(A^{\prime}{ }_{v c}=0\right)$. However, for an orifice being subjected to a bias flow then the discharge coefficient (based on the mean flow field) is lower than the plenum fed value. Hence, a change in the area of the vena contracta is therefore observed during an acoustic cycle. Finally the above equation is consistent with the admittance characteristics observed in the current data set and observed by several other authors since by using (Eq. (11), (12) and (16)) then:

$$
\delta_{q S}=\frac{\rho \omega Q^{\prime}}{\widehat{p}}=\frac{\rho \omega\left(u_{j}^{\prime} A_{v c}+A^{\prime}{ }_{v c} U_{j}\right)}{\rho U_{j} u_{j}^{\prime}}=\frac{\pi}{2}\left(\frac{\omega R}{U_{b}}\right) C_{d(p)}^{2}
$$

An explanation is therefore provided as to why the introduction of grazing flow has little effect on the measured orifice admittance. This data is presented for the plain orifice liner in Figure 17 and 
shows good agreement up to a Strouhal number of 0.5. For the skewed orifice liner good agreement is observed up to a Strouhal number of 0.35 . In this case the skewed orifice geometry means inertial effects are likely to become more significant at lower Strouhal numbers, and this is indicated by the data presented. Above these Strouhal numbers the admittance does vary relative to that indicated by Eq. (17), although it should be noted that the admittance values derived from each experimental operating condition continue to remain comparable at a given Strouhal number. The deviation from Eq. (17) at the higher Strouhal numbers may indicate that the flow is no longer quasi-steady (and hence inertial effects start to become significant). Alternatively, for plenum fed plain orifices Lawn [7] observed that at Strouhal numbers greater than 0.3 there is some uncertainty in the resistance (and hence admittance) values obtained from low frequency theories (e.g. such as that outlined by Howe [4]. This may also account for the observed deviations from Eq. (17) at the higher Strouhal numbers tested.

With the exception of the lowest velocity ratio tested $\left(U_{b} / U_{g}>0.34\right)$, for a plain orifice liner (L/D 0.2) the above analysis indicates that based on the knowledge of the plenum fed discharge coefficient the unsteady flow characteristics can be estimated. This is for a range of bias to grazing flow velocity ratios $U_{b} / U_{g}>0.64$ and for conditions where the acoustic velocity is less than, or equal to, the mean bias flow (i.e. $U_{b} \geq u^{\prime}{ }_{b}$ ). Using this information the absorption characteristics of the liner can be estimated. For a liner with a modified geometry the same basic characteristics are observed although, not surprisingly, relative to the plain geometry there are variations in the discharge coefficient at a given Strouhal number.

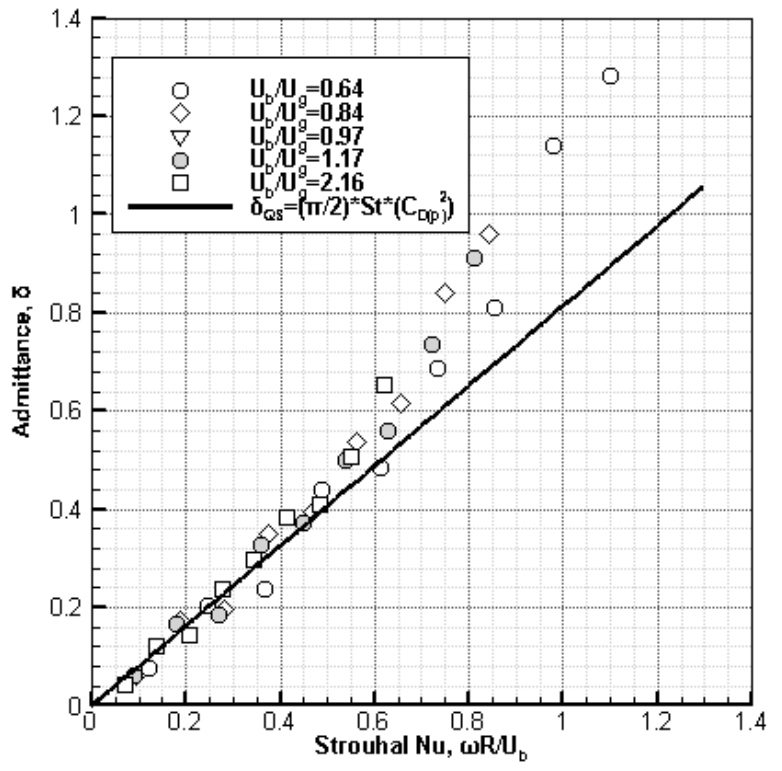

(a)

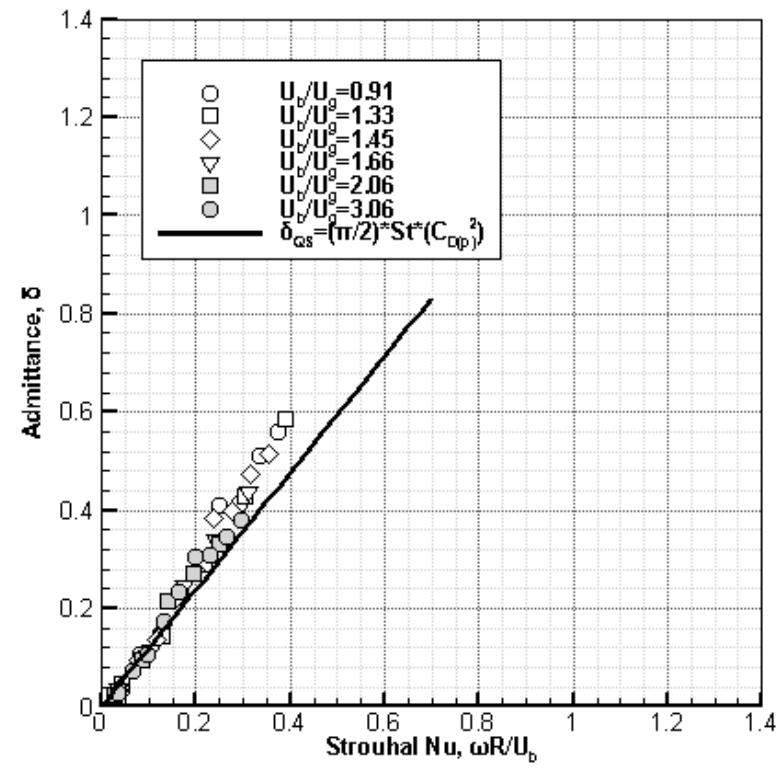

(b)

Figure 17 Measured admittance values and its respective measured plenum discharge coefficient for (a) plain liner and (b) skewed liner. 


\section{Conclusions}

Experimental measurements of the mean and unsteady flow field have been undertaken on 2 perforated liner configurations which incorporate both plain and skewed orifice configurations. For the majority of the results presented the liners were supplied from a passage. This enabled each liner to be subjected to a flow that grazes the upstream side of each liner orifice, whilst the pressure loss across the liner could be varied to generate a bias flow through each orifice. In this way each liner could be subjected to a range of grazing and bias flow combinations. However, tests were also undertaken in which each liner was fed from a plenum.

For the mean flow field measured discharge coefficients are presented, and it is shown that these are dominated by the grazing to bias flow velocity ratio. This is consistent with the findings presented by previous workers for similar configurations. A simple model is presented that captures, at least to leading order, the variation in discharge coefficient with velocity ratio for the range of conditions tested. In addition, measurements have been made of the unsteady flow field as each liner was subjected to a harmonic pressure variation associated with incident plane acoustic waves. The unsteady flow field characteristics are mainly presented in terms of acoustic admittance and, for each liner, comparable values were observed at a given Strouhal number (based on the applied frequency and mean bias flow velocity). This includes when the liners were plenum fed and when subjected to a range of bias to grazing flow velocity ratios (and hence discharge coefficients). During an acoustic cycle it is demonstrated that the observed characteristics are consistent with variations in both (i) velocity and (ii) the area of the downstream vena contracta. The exception to this was at the lowest bias to grazing flow velocity ratio tested $\left(U_{b} / U_{g} \sim 0.64\right)$ where some variation in the admittance was observed. This is thought to be the point where the orifice flow starts to impact with the rear of the orifice.

The above conclusions mean that using the simple expression for the variation of hole discharge coefficient with velocity ratio, the acoustic admittance characteristics of the liner can be obtained from a simple measurement of the discharge coefficient (when operating under plenum fed conditions). This is for the range of conditions quoted.

\section{Acknowledgements}

The authors would like to acknowledge the financial support of Rolls-Royce plc. who supported this work. In addition, the authors would like to acknowledge Ashley Barker for the experimental support provided. 


\section{References}

[1] V. Bellucci, P. Flohr, C.O. Paschereit, Numerical and experimental study of acoustic damping generated by perforated screens, AIAA J. 42 (2004) 1543-1549.

[2] A.P. Dowling, I.J. Hughes, Sound absorption by a screen with a regular array of slits, J. Sound Vib. 156 (1992) 387-405.

[3] S. Forster, U. Michel, Experimental investigation of the dissipation of acoustic energy in perforated walls with bias flow, Int. Colloq. Combust. Noise Control. (2003) 12-15.

[4] M.S. Howe, On the theory of unsteady high Reynolds number flow through a circular aperture, in: Proc. R. Soc. London A Math. Phys. Eng. Sci., The Royal Society, 1979: pp. 205223.

[5] T. Luong, M.S. Howe, R.S. McGowan, On the Rayleigh conductivity of a bias-flow aperture, J. Fluids Struct. 21 (2005) 769-778.

[6] J. Rupp, Acoustic absorption and the unsteady flow associated with circular apertures in a gas turbine environment, 2013.

[7] C.J. Lawn, The acoustic impedance of perforated plates under various flow conditions relating to combustion chamber liners, Appl. Acoust. 106 (2016) 144-154.

[8] J.W.S. Rayleigh, R.B. Lindsay, The theory of sound, Dover, 1945.

[9] I.J. Hughes, A.P. Dowling, The absorption of sound by perforated linings, J. Fluid Mech. 218 (1990) 299.

[10] X. Jing, X. Sun, Experimental investigations of perforated liners with bias flow, J. Acoust. Soc. Am. 106 (1999) 2436-2441.

[11] X. Jing, X. Sun, Effect of Plate Thickness on Impedance of Perforated Plates with Bias Flow, AIAA J. 38 (2000) 1573-1578.

[12] H. Rouse, A.-H. Abul-Fetouh, Characteristics of irrotational flow through axially symmetric orifices, J. Appl. Mech. ASME. 17 (1950) 421-426.

[13] J.D. Eldredge, A.P. Dowling, The absorption of axial acoustic waves by a perforated liner with bias flow, J. Fluid Mech. 485 (2003).

[14] C. Heuwinkel, L. Enghardt, I. Rohle, Experimental Investigation of the Acoustic Damping of Perforated Liners with Bias Flow, in: 13th AIAA/CEAS Aeroacoustics Conf. (28th AIAA Aeroacoustics Conf., American Institute of Aeronautics and Astronautics, Reston, Virigina, 2007.

[15] C. Lahiri, L. Enghardt, F. Bake, S. Sadig, M. Gerendás, Establishment of a High Quality Database for the Acoustic Modeling of Perforated Liners, J. Eng. Gas Turbines Power. 133 (2011).

[16] S. Mendez, J.D. Eldredge, Acoustic modeling of perforated plates with bias flow for LargeEddy Simulations, J. Comput. Phys. 228 (2009) 4757-4772. 
[17] A. Andreini, C. Bianchini, B. Facchini, F. Simonetti, A. Peschiulli, Assessment of Numerical Tools for the Evaluation of the Acoustic Impedance of Multi-Perforated Plates, in: Vol. 2 Combust. Fuels Emiss. Parts A B, ASME, 2011: pp. 1065-1077.

[18] D. Tonon, E.M.T. Moers, A. Hirschberg, Quasi-steady acoustic response of wall perforations subject to a grazing-bias flow combination, J. Sound Vib. 332 (2013) 1654-1673.

[19] T. Rogers, A.S. Hersh, The effect of grazing flow on the steady state resistance of squareedged orifices, in: Proc. Second AIAA Aeroacoustics Conf., 1976.

[20] X. Sun, X. Jing, H. Zhang, Y. Shi, Effect of grazing-bias flow interaction on acoustic impedance of perforated plates, J. Sound Vib. 254 (2002) 557-573.

[21] Biron D, Simon F, Characteristics of acoustic sources, 2002.

[22] A. Cummings, W. Eversman, High amplitude acoustic transmission through duct terminations: Theory, J. Sound Vib. 91 (1983) 503-518.

[23] A.F. Seybert, D.F. Ross, Experimental determination of acoustic properties using a twomicrophone random-excitation technique, J. Acoust. Soc. Am. 61 (1977) 1362-1370.

[24] G. Kooijman, A. Hirschberg, J. Golliard, Acoustical response of orifices under grazing flow: Effect of boundary layer profile and edge geometry, J. Sound Vib. 315 (2008) 849-874. 